\title{
An Assessment of Frequent Haemolytic Crisis in G6PD Deficiency Subjects Linked with Chronic Disease States in Al Ahsa Community, Saudi Arabia
}

\author{
Promise Emeka1 ${ }^{*}$, Hussien Al Hilal2 ${ }^{2}$, Afzal H. Asif ${ }^{3}$, Ahmed Almukhalaf', Tahir Khan ${ }^{4}$ \\ ${ }^{1}$ Department of Pharmaceutical Science, College of Clinical Pharmacy, King Faisal University, Al Hofuf, Saudi \\ Arabia \\ ${ }^{2}$ College of Clinical Pharmacy, King Faisal University, Al Hofuf, Saudi Arabia \\ ${ }^{3}$ Department of Pharmacy Practice, College of Clinical Pharmacy, King Faisal University, Al Hofuf, Saudi Arabia \\ ${ }^{4}$ School of Pharmaceutical Science, Monash University, Jalan Lagoon Selatan, Selangor Darul Ehsan, Malaysia \\ Email: ${ }^{*}$ pemeka@kfu.edu.sa
}

Received 28 April 2015; accepted 23 May 2015; published 26 May 2015

Copyright (C) 2015 by authors and Scientific Research Publishing Inc.

This work is licensed under the Creative Commons Attribution International License (CC BY). http://creativecommons.org/licenses/by/4.0/

cC) (i) Open Access

\section{Abstract}

The main treatment strategy for glucose-6-phosphate dehydrogenase (G6PD) deficiency is averting the use of oxidative precipitants like drugs or foods that trigger haemolysis. However, subjects could experience acute crisis in a comorbidity state of diabetes, hypertension or infection. In addition, the condition could in turn predispose carriers to these chronic diseases. Aim of the study was to evaluate the frequency of haemolytic crisis in carriers with attendant chronic diseases, and also assess awareness and knowledge of aggravated reactions from these conditions. 282 subjects consented and participated in the study. A cross-sectional semi-structured interview questionnaire conducted from May to August 2013 was adopted. Questions focused on demographics, awareness and when disease was diagnosed, type and frequency of crisis, family history, screening and presence of other diseases and awareness of trigger from these conditions. A total of $69.9 \%$ were G6PD deficiency gene carriers and mostly fell within the age group of $31-40(43.6 \%) .75 .6 \%$ of the carriers were not aware that other disease conditions could exacerbate crisis. Non-drug related crisis was $85.3 \%$ compared with 14.7 drug related reactions. Out of the $69.9 \%$ carriers, $17.3 \%$ are diabetics, $18.3 \%$ of them are hypertensive and $25.9 \%$ are with bleeding disorders. Also, 29.1\% had frequent episodes with bacterial infection. Symptoms experienced that were not drug related included, $44.8 \%$ attacks of pallor, $25.3 \%$ jaundice, $28.5 \%$ with shortness of breath, while $21.7 \%$ had dark urine frequently. No routine screening for other diseased conditions was carried out for these subjects despite experiencing frequent crisis that were not drug related. Carriers

${ }^{*}$ Corresponding author.

How to cite this paper: Emeka, P., Al Hilal, H., Asif, A.H., Almukhalaf, A. and Khan, T. (2015) An Assessment of Frequent Haemolytic Crisis in G6PD Deficiency Subjects Linked with Chronic Disease States in Al Ahsa Community, Saudi Arabia. Health, 7, 625-632. http://dx.doi.org/10.4236/health.2015.75074 
with other diseased conditions experienced more non-drug related crisis and were not aware of it. Keywords

G6PD, Haemolytic Crisis, Carriers, Chronic Diseases, Symptoms

\section{Introduction}

Glucose-6-phosphate dehydrogenase (G6PD) deficiency is a disease of the red blood cell (RBC) which exposes patients to intravascular haemolysis. The disease is a characteristic genetic enzymic disorder of RBC, which predisposes the cells to oxidative injury [1] [2]. The deficiency is believed to be caused by mutation in the G6PD gene, an X-linked hereditary genetic defect [3] often predominant in males [4]. Reports have shown that about 400 million people are affected worldwide and it is highly polymorphic [5]-[7]. The prevalence of G6PD disorder has been reported in many areas of the world including the Middle East [8] [9]. It was first reported in Saudi Arabia in 1965 [10] and evidence from other studies has shown that G6PD deficiency occurs in all provinces of Saudi Arabia and particularly in the eastern region [3] [11]. Because there is no routine testing to identify subjects who carry this deficient gene, most people became aware only when there is a crisis either to drugs or to food. According to reports, certain disease states can aggravate the severity of G6PD deficiency crisis apart from drugs or foods [12]. Chronic diseases like diabetes mellitus, hypertension and bacterial infections causing pneumonia have all been implicated in acute severe crisis amongst G6PD deficiency subjects [12] [13]. Epidemiological data suggested a link between G6PD deficiency and diabetes mellitus [14]. This association could be due to a relationship between insulin secretion and G6PD activity [14] [15]. On the other hand, a higher incidence of hypertension and idiopathic cardiomyopathy has been associated with G6PD deficiency [16]. This is because pressure overload induces redox stress in the presence of G6PD deficiency, enhancing the risk potential for crisis [17]. Wiesenfeld et al., [18] in their study, reported an increase in blood pressure amongst G6PD deficiency subjects. Furthermore, G6PD deficient subjects appear to be more susceptible to bacterial infection than normal individuals [19]. Infections by bacterial agents were reported to trigger severe crisis in neonates as well because they may on their own induce oxidative stress [20]. The effect of bacterial infection on G6PD deficient subjects is reported to be mainly due to reduced phagocyte activity, and a high rate of apoptotic activity occasioned by redox imbalance [20] [21]. Therefore, chronic disease states can exacerbate haemolytic crisis in G6PD deficiency subjects and hence can be said to an important predisposing risk factor. Level of education could be a factor for not knowing that existence of other disease could be detrimental to their well-being. The objective of this assessment was to a) to evaluate the frequency of haemolytic crisis in those with attendant chronic diseases; b) appraise awareness and knowledge of aggravated reactions from these conditions among deficient subjects.

\section{Method}

Study was approved by the Deanship for Scientific Research, King Faisal University, Al Hofuf Saudi Arabia. A cross-sectional semi-structured interview questionnaire conducted from May to August 2013 was adopted. A total of 282 subjects responded, were interviewed and completed the questionnaire. Eligibility criteria included males who are indigenes, born in $\mathrm{Al}$ Ahsa and with resident families within the community. They also included indigenous males with age of $\geq 8$ and above. Any male within this age group who is not an indigene like expatriates and visitors were excluded from the study. The interview focused on issues like demographics, awareness of the disease and when it was diagnosed, type of reactions experienced, family history, symptoms experienced, screening for other diseased conditions, presence of other disease conditions and symptoms experienced. The questionnaire, which was in English language, was also translated into Arabic language to ensure that all respondents were able to read and understand the questionnaire in order to give their consent as well. Participation was voluntary, the purpose of the study was explained to respondents, and they gave their consent verbally and willingly. Also, the selection of respondents was carried out to represent the entire Al Ahsa community, particularly in Hofuf, Mubaraz areas and all the surrounding villages within Al Ahsa region. Confidentiality of names of respondents and all personal information collected were assured. Frequent crisis was classified in this study as experiencing crisis every month that is not drug induced. Symptoms considered as relevant to crisis include dark 
coloured urine, shortness of breath, and attack of pallor.

\section{Statistics}

Data collected were first recorded on excel spread sheet and analysed with the aid of IBM Statistical Package for Social Sciences (SPSS) 19. Descriptive statistics was employed to determine the frequencies. Student's T-test was used to compare group frequencies and statistical significant differences were set at $\mathrm{p}<0.05$.

\section{Results}

Age distribution of respondents display a well sampled questionnaire, which ranged from $<10$ to $>50$ years. Majority of the respondents fell under the age group of 31 - 41 years, representing $40.1 \%$ out the total number interviewed (Table 1). This group also represented the working class as they are all gainfully employed.

Figure 1 shows the educational levels of respondents which revealed that they were educated up to at least intermediate level. This represented a total percentage of 94.7. It therefore means that they could all read and understand the content of the questionnaire which facilitated the process of the interview. From the analysis of the data, we also found out that $50.7 \%$ of the respondents admitted to intermarriage of first cousin. Additionally, only $7.5 \%$ of the total sampled population has ever been evaluated for drug reaction. This number is inclusive of both carriers and non-carriers of the defective gene.

Out of the total number of respondents sampled, 69.9\% are carriers of G6PD deficiency gene (Figure 2), showing that the population had a significant $(\mathrm{p}<0.05)$ presence of the disease.

Interestingly, age group of 31 - 40 years that was the highest number of respondents was also the most G6DP disorder affected group with 43.6\%. 21 - 30 years age group with 30.5\% (Figure 3) followed this. Remarkably, $99.4 \%$ of them were diagnosed only during crisis.

Our result also showed that amongst the G6PD deficient subjects, only $14.7 \%$ had histories of drug reaction,

Table 1. Illustrates the age distribution of respondents sampled.

\begin{tabular}{ccc}
\hline Age (years) & Number & Percentage (\%) \\
\hline 10 & 4 & 1.4 \\
$11-20$ & 19 & 6.7 \\
$21-30$ & 98 & 34.8 \\
$31-40$ & 113 & 40.1 \\
$41-50$ & 38 & 13.5 \\
$>50$ & 10 & 3.5 \\
\hline
\end{tabular}

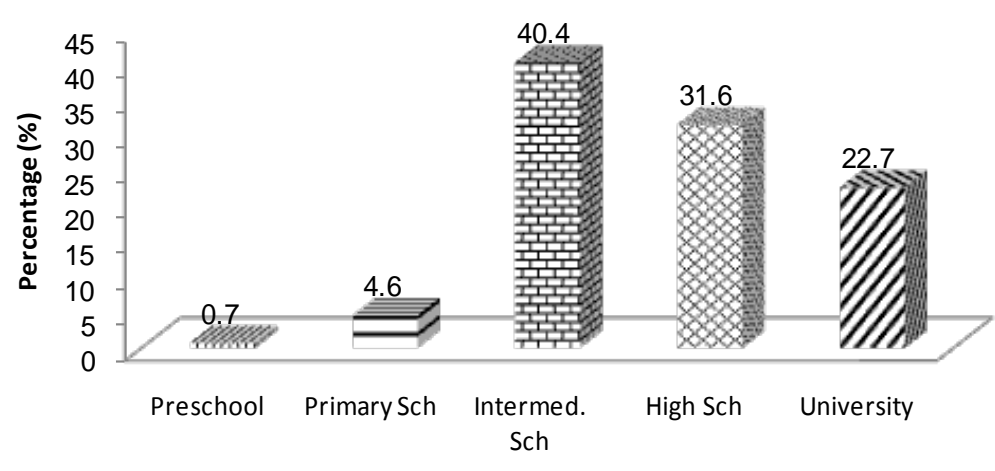

Education Levels of respondents

Figure 1. Showing the educational levels distribution of respondents. Sch = School. 


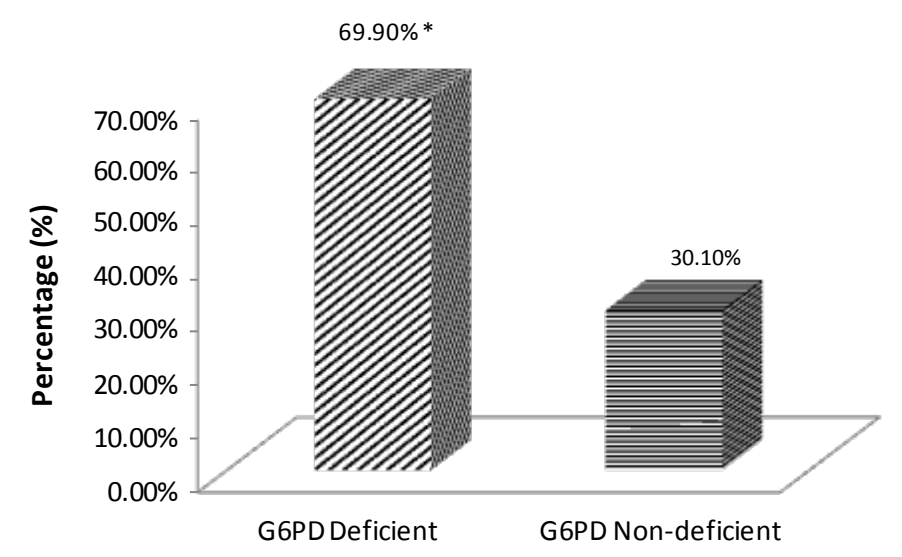

Figure 2. Showing distribution pattern of G6PD deficiency syndrome amongst the sampled population. * $(p<0.05)$; G6PD = Glocose-6-phosphate dehydrogenase deficiency.

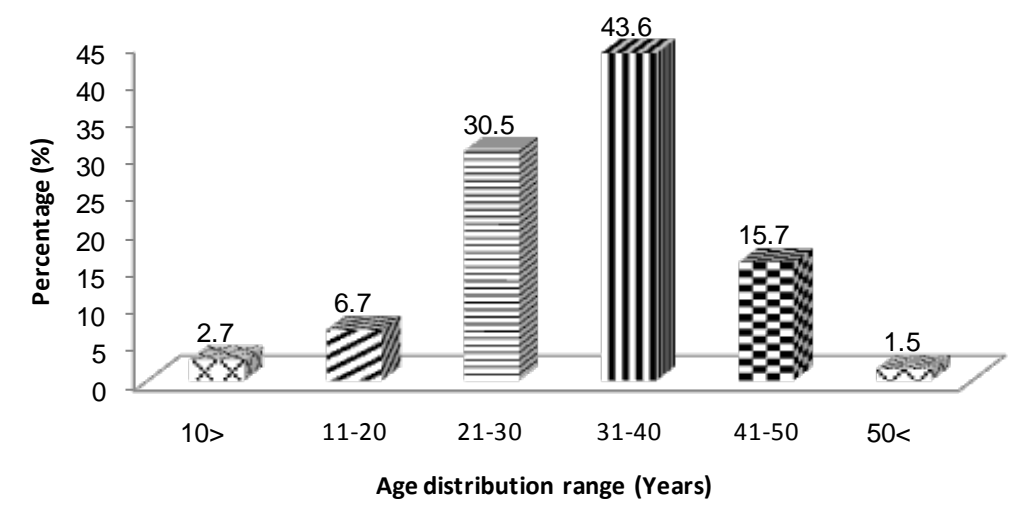

Figure 3. Distribution of G6PD deficiency within the different age groups.

whereas $85.3 \%$ did not (Figure 4). Again, this shows that subjects had a significant $(\mathrm{p}<0.05)$ non-drug related haemolytic crisis more frequently and this could be due to the presence of comorbidity.

Illustration on Figure 5 demonstrated that carriers had other associated disease conditions like, diabetes mellitus, hypertension, sickle cell disease, kidney disease, liver disease and bleeding disorders. They represented $17.3 \%, 18.3 \%, 7.6 \%, 1.0 \%, 4.6 \%$, and $25.9 \%$ respectively. Added to this is a history of recurrent infection representing $29.9 \%$.

Figure 6 shows that significant number of those who are G6PD deficient did not have the knowledge that the presence of another disease could exacerbate their haemolytic crisis. The represented $99.5 \%$ and very significant compared to those who were aware $(\mathrm{p}<0.05)$.

Results also revealed symptoms of acute haemolytic crisis that carriers of G6PD deficiency syndrome frequently experienced which were not drug related. The frequent symptoms include pallor (49.8\%) jaundice (25.3\%), dark urine (21.7\%), shortness of breath $28.5 \%)$, and with its attendant infections which are regular features as shown in Figure 7.

\section{Discussion}

G6PD deficiency is an inherited disease carrying with it the inability to provide reductive potential in form of Nicotinamide adenine dinucleotide phosphate (NADPH), which protects the RBC from haemolysing [22]. In Saudi Arabia, several studies have shown that different frequencies of the disease exist in different region [3]. However, in eastern region communities, evidence shows that the disorder does exist and appears to be high in prevalence as well [8]. In this assessment, $69.9 \%$ of the total respondents are carriers of the deficient gene, Also, $50.7 \%$ of the respondent admitted to intermarriage with first cousin within the family. Most of the respondents 


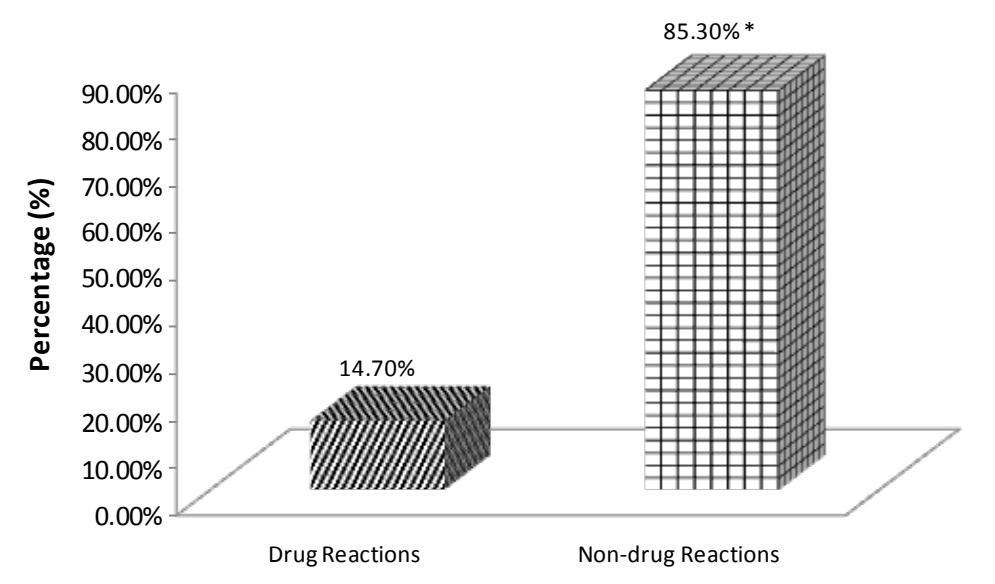

Figure 4. Drug and non-drug reactions distribution amongst G6PD deficient subjects sampled. ${ }^{*}(\mathrm{p}<0.05)$.

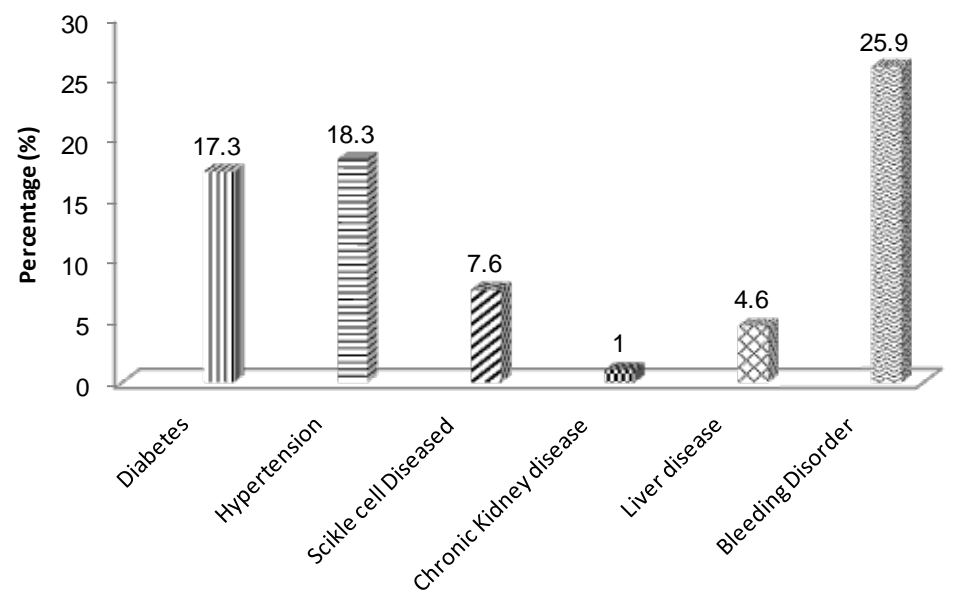

Figure 5. Chronic disease states co-existing amongst carriers of G6PD subjects sampled.

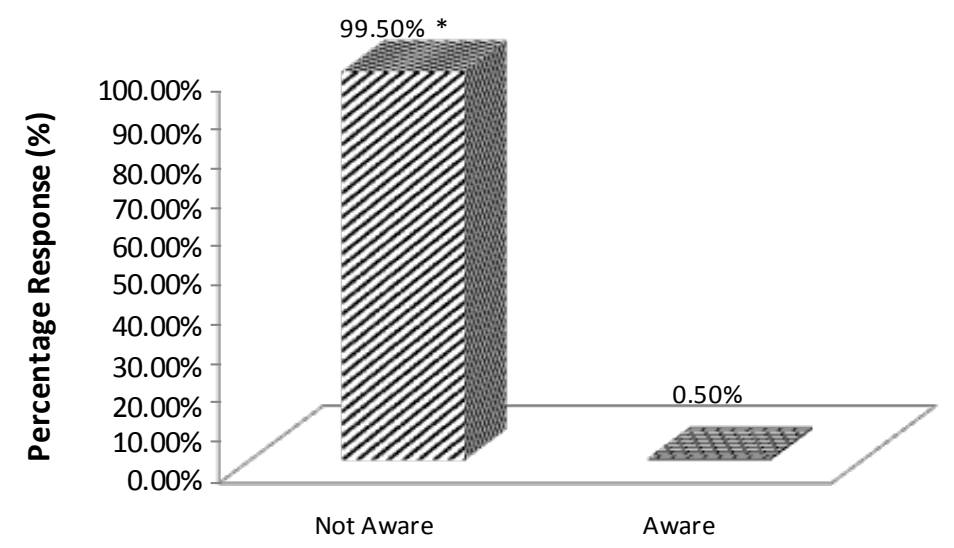

Figure 6. Subjects' awareness and knowledge of aggravated reactions in comorbidity state. ${ }^{*}(\mathrm{p}<0.05)$.

were found to be of intermediate level of education and within the age of range of 31 - 40 years who are majorly carriers of this disorder. Drugs precipitating crisis and severe reactions in G6PD subjects have been extensively studied according to literature. Our findings reveal that only $14.7 \%$ of the carriers of the deficiency had a history 


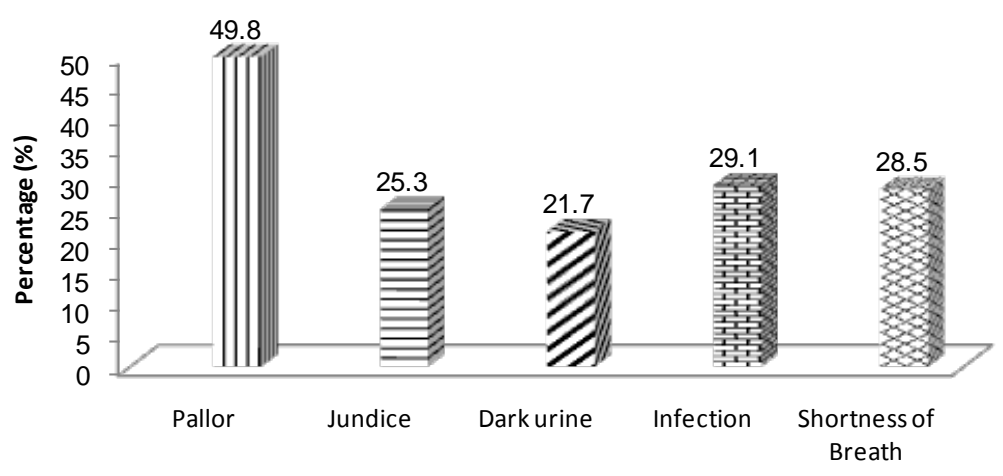

Aggravated symptoms experienced not related to drugs or food

Figure 7. Aggravated symptoms associated with frequent crisis amongst G6PD deficiency subjects that are not drug related.

of drug reaction. However, other factors can aggravate haemolysis if they co-exist in subjects. These factors can incite reaction that might be fatal [12]. Metabolic disease like diabetes mellitus, a situation of hyperglycaemia and ketoacidosis has been reported to be a potentially precipitating condition [12] [23]. We found that $17.3 \%$ of the respondents are diabetic and did not know that these scenarios could happen. Severe hyperglycaemia could further decrease G6PD activity and trigger crisis [24]. There is evidence that infection by salmonella, beta haemolytic streptococcus and E coli could predispose subjects to some of the symptoms of severe haemolytic crisis particularly with respiratory tract infection. This is due to oxidative reaction generated by macrophage phagocytic behaviour [12]. In this study, 29.1\% of the subjects sampled reported frequent episodes of infection. These could be responsible for some of the symptoms the respondents experienced which were not drug related. Hypertension is another factor that can portend danger to carriers of G6PD deficient gene. This is because hypertension can cause RBC to become fragmented. Therefore, in hypertensive subjects stressed cells will be highly sensitive to fragmentation [25]. Our assessment revealed that $18.3 \%$ of the respondents are hypertensive. As a result, G6PD deficiency subjects were experiencing acute haemolytic crisis like jaundice, attacks of pallor, dark urine and shortness of breath. In such subjects, information and counselling will be helpful and will reduce hospitalization by keeping the blood pressure stable. Our study also showed that $99.4 \%$ of the carriers of the disease were diagnosed during crisis and only $50.8 \%$ of them received counselling about drugs and food that might be detrimental to them. This study has shown that although a significant number of the respondents are aware of the disease, majority are not aware that it is an inherited disorder that is predominant in males. In addition, that co-existence of other diseased conditions could trigger severe haemolysis is not to their knowledge. The community is a high-risk population, as G6PD deficiency is known and reported with a high percentage of diabetic and hypertensive patients. Therefore, the risk of experiencing acute symptoms is potentially high.

Therefore, screening for diabetes, hypertension and monitoring for infection, which are implicated triggering factors for haemolytic crisis, should be undertaken. This is in order to mitigate and prevent severe haemolysis and to improve quality of life of suffering subjects. An accurate index of diabetes, hypertension or even bacterial infection linked G6PD crisis is needed as an indication of their relationship. In such patients, it is advocated that one should be less aggressive in treating hyperglycaemia to avoid rapidly induced euglycaemia, which may cause haemolysis. Published case study reports show that ketosis prone G6PD deficient diabetic patient experienced haemolytic crisis during a decompensation of hyperglycaemia which might precipitate a sudden change in glucose level [24] [26] [27]. The limitation for this study is that the sample size is small and needs to be expanded for a study with this importance. Also the study design does not make room for comparism with control population. Hospital records of carriers were not examined.

\section{Conclusion}

Therefore, the presence of chronic diseased states and or bacterial infections can be predisposing factors that may frequently, cause haemolytic crisis among G6PD deficient subjects in accordance to previous reports. There should be a paradigm shift on the assessment and treatment strategy for G6PD deficiency patients other than averting the use of oxidative precipitants known to cause haemolysis. Carriers should be aware that comorbidity 
states could potentially precipitate sever crisis, leading to increased medical cost due to hospitalization. We strongly recommend that people with G6PD deficiency who also have conditions like diabetes mellitus or hypertension, should be aware that these diseases could potentially trigger sever crisis just like some drugs or food. Information about potential interaction with these conditions should be provided as part of health care informatics. This is because adequate BP and blood sugar control will minimize acute haemolytic crisis in comorbidity subjects.

\section{Acknowledgements}

Authors wishes to acknowledge the Deanship for Scientific Research, King Faisal University, Al Hofuf Saudi Arabia for the support given us to carry out this research project.

\section{Conflict of Interest}

Authors have no conflict of interest to declare.

\section{Funding}

This study was not supported by any funding from any organisation or institution.

\section{References}

[1] Al-Jaouni, S.K., Jarullah, J., Azhar, E. and Moradkhani, K. (2011) Molecular Characterization of Glucose-6-Phosphate Dehydrogenase Deficiency in Jeddah, Kingdom of Saudi Arabia. BMC Research Notes, 4, 436. http://dx.doi.org/10.1186/1756-0500-4-436

[2] Pathak, R.R., Chhaiya, S.B. and Mehta, D.S. (2013) Prevalence of G6PD Deficiency versus Oxidizing Drugs: A Survey in the Tertiary Care Hospital. International Journal of Basic Clinical Pharmacology, 2, 170-176. http://dx.doi.org/10.5455/2319-2003.ijbcp20130310

[3] Alabdulaali, M.K., Alayed, K.M., Alshaikh, A.F. and Almashhadani, S.A. (2010) Prevalence of Glucose-6-Phosphate Dehydrogenase Deficiency and Sickle Cell Trait among Blood Donors in Riyadh. Asian Journal of Transfusion Science, 4, 31-33. http://dx.doi.org/10.4103/0973-6247.59389

[4] Al-Sweedan, S.A., Jdaitawi, H., Khriesat, W.M., Khader, Y.Y. and Al-Rimawi, H.S. (2009) Predictors of Severe Hemolysis in Patients with Glucose-6-Phosphate Dehydrogenase Deficiency Following Exposure to Oxidant Stresses. Hematology/Oncology and Stem Cell Therapy, 2, 354-357. http://dx.doi.org/10.1016/S1658-3876(09)50025-8

[5] WHO Working Group (1989) Glucose-6-Phosphate Dehydrogenase Deficiency. Bulletin of the World Health Organization, 67, 601-611.

[6] Beutler, E. (2008) Glucose-6-Phosphate Dehydrogenase Deficiency: A Historical Perspective. Blood, 111, 16-24. http://dx.doi.org/10.1182/blood-2007-04-077412

[7] Santana, M.S., Monteiro, W.M., Costa, M.R., Sampaio, V.S., Brito, M.A., Lacerda, M.V. and Alecrim, M.G. (2014) High Frequency of Diabetes and Impaired Fasting Glucose in Patients with Glucose-6-Phosphate Dehydrogenase Deficiency in the Western Brazilian Amazon. American Journal of Tropical Medicine and Hygiene, 91, 74-76. http://dx.doi.org/10.4269/ajtmh.13-0032

[8] Nasserullah, Z., Al Jame, A., Abu Srair, H., Al Qatari, G., Al Naim, S., Al Aqib, A., et al. (1998) Neonatal Screening for Sickle Cell Disease, Glucose-6-Phosphate Dehydrogenase Deficiency and A-Thalassemia in Qatif and Al Hasa. Annals of Saudi Medicine, 18, 289-292.

[9] Al-Ali, A.K., Al-Mustafa, Z.H., Al-Madan, M., Qaw, F. and Al-Ateeq, S. (2002) Molecular Characterization of Glucose-6-Phosphate Dehydrogenase Deficiency in the Eastern Province of Saudi Arabia. Clinical Chemistry and Laboratory Medicine, 40, 814-816. http://dx.doi.org/10.1515/CCLM.2002.141

[10] Gelpi, A.P. (1965) Glucose-6-Phosphate Dehydrogenase Deficiency in Saudi Arabia. Blood, 25, 486-493.

[11] Alhamdan, N.A., Almazrou, Y.Y., Alswaidi, F.M. and Choudhry, A.J. (2007) Premarital Screening for Thalassemia and Sickle Cell Disease in Saudi Arabia. Genetics in Medicine, 9, 372-377. http://dx.doi.org/10.1097/GIM.0b013e318065a9e8

[12] Elyassi, A.R. and Rowshan, H.H. (2009) Perioperative Management of the Glucose-6-Phosphate Dehydrogenase Deficient Patient: A Review of Literature. Anesthesia Progress, 56, 86-91. http://dx.doi.org/10.2344/0003-3006-56.3.86

[13] Phillips, S.M. and Silvers, N.P. (1969) Glucose-Phosphate Dehydrogenase Deficiency, Infectious Hepatitis, Acute Hemolysis, and Renal Failure. Annals of Internal Medicine, 70, 99-104. http://dx.doi.org/10.7326/0003-4819-70-1-99 
[14] Heymann, A.D., Cohen, Y. and Chodick, G. (2012) Glucose-6-Phosphate Dehydrogenase Deficiency and Type 2 Diabetes. Diabetes Care, 35, e58. http://dx.doi.org/10.2337/dc11-2527

[15] Zhang, Z., Liew, C.W., Handy, D.E., Zhang, Y., Leopold, J.A., Hu, J., Guo, L., Kulkarni, R.N., Loscalzo, J. and Stanton, R.C. (2010) High Glucose Inhibits Glucose-6-Phosphate Dehydrogenase, Leading to Increased Oxidative Stress and Beta-Cell Apoptosis. The FASEB Journal, 24, 1497-1505. http://dx.doi.org/10.1096/fj.09-136572

[16] Hecker, P.A., Leopold, J.A., Gupte, S.A., Recchia, F.A. and Stanley, W.C. (2013) Impact of Glucose-6-Phosphate Dehydrogenase Deficiency on the Pathophysiology of Cardiovascular Disease. AJP: Heart and Circulatory Physiology, 304, H491-H500. http://dx.doi.org/10.1152/ajpheart.00721.2012

[17] Hecker, P.A., Lionetti, V., Ribeiro Jr., R.F., Rastogi, S., Brown, B.H., O’Connell, K.A., Cox, J.W., Shekar, K.C., Gamble, D.M., Sabbah, H.N., Leopold, J.A., Gupte, S.A., Recchia, F.A. and Stanley, W.C. (2013) Glucose 6-Phosphate Dehydrogenase Deficiency Increases Redox Stress and Moderately Accelerates the Development of Heart Failure. Circulation: Heart Failure, 6, 118-126. http://dx.doi.org/10.1161/CIRCHEARTFAILURE.112.969576

[18] Wiesenfeld, S.L., Petrakis, N.L., Sams, B.J., Collen, M.F. and Cutler, J.L. (1970) Elevated Blood Pressure, Pulse Rate and Serum Creatinine in Negro Males Deficient in Glucose-6-Phosphate Dehydrogenase. New England Journal of Medicine, 282, 1001-1002. http://dx.doi.org/10.1056/NEJM197004302821804

[19] Clark, M. and Root, R.K. (1979) Glucose-6-Phosphate Dehydrogenase Deficiency and Infection: A Study of Hospitalized Patients in Iran. Yale Journal of Biology and Medicine, 52, 169-179.

[20] Hsieh, Y.-T., Lin, M.-H., Ho, H.-Y., Chen, L.-C., Chen, C.-C. and Shu, J.-C. (2013) Glucose-6-Phosphate Dehydrogenase (G6PD)-Deficient Epithelial Cells Are Less Tolerant to Infection by Staphylococcus aureus. PLoS ONE, 8, e79566. http://dx.doi.org/10.1371/journal.pone.0079566

[21] Nowiński, A., Jabłońska-Skwiecińska, E., Wojda, E., Bieleń, P., Ptak, J., Sliwinski, P. and Górecka, D. (2007) Community-Acquired Pneumonia Complications in a Patient with Hereditary Glucose-6-Phosphate Dehydrogenase Deficiency. Pneumonologia i Alergologia Polska, 75, 283-288.

[22] Luzzatto, L., Mehta, A. and Vulliamy, T. (2001) Glucose 6-Phosphate Dehydrogenase Deficiency. In: Scriver, C.R., Beaudet, A.L., Sly, W.S. and Valle, D., Eds., The Metabolic and Molecular Bases of Inherited Disease, 8th Edition, McGraw-Hill, New York, 4517-4533.

[23] Beutler, E. (1994) G6PD Deficiency. Blood, 84, 3613-3636.

[24] Carette, C., Dubois-Laforgue, D., Gautier, J.F. and Timsit, J. (2011) Diabetes Mellitus and Glucose-6-Phosphate Dehydrogenase Deficiency: From one Crisis to Another. Diabetes \& Metabolism, 37, 79-82. http://dx.doi.org/10.1016/j.diabet.2010.09.004

[25] Moore, G.S. and Calabrese, E.J. (1979) The Possible Role of Hypertension in Aggravating Hemolytic Episodes in G-6PD Deficient Persons. Medical Hypotheses, 5, 453-462. http://dx.doi.org/10.1016/0306-9877(79)90111-7

[26] Gu, X.J., Chen, S.P., Ge, S.J., Zheng, L.Q., Wang, D.W. and Shen, F.X. (2013) G6PD Deficiency-Induced Hemolysis in a Chinese Diabetic Patient: A Case Report with Clinical and Molecular Analysis. Acta Diabetologica, 50, 89-92. http://dx.doi.org/10.1007/s00592-010-0236-y

[27] Agarwal, A., Nayak, M.D., Patil, A. and Manohar, C. (2013) Glucose 6 Phosphate Dehydrogenase Deficiency Unmasked by Diabetic Ketoacidosis: An Underrated Phenomenon. Journal of Clinical and Diagnostic Research, 7, 30123013. http://dx.doi.org/10.7860/jcdr/2013/6159.3892 